(c) American Dairy Science Association, 2005.

\title{
A Microfiltration Process to Maximize Removal of Serum Proteins from Skim Milk Before Cheese Making*
}

\section{B. K. Nelson and D. M. Barbano}

Northeast Dairy Foods Research Center, Department of Food Science, Cornell University, Ithaca, NY 14853

\begin{abstract}
Microfiltration (MF) is a membrane process that can separate casein micelles from milk serum proteins (SP), mainly $\beta$-lactoglobulin and $\alpha$-lactalbumin. Our objective was to develop a multistage MF process to remove a high percentage of SP from skim milk while producing a low concentration factor retentate from microfiltration (RMF) with concentrations of soluble minerals, nonprotein nitrogen (NPN), and lactose similar to the original skim milk. The RMF could be blended with cream to standardize milk for traditional Cheddar cheese making. Permeate from ultrafiltration (PUF) obtained from the ultrafiltration (UF) of permeate from MF (PMF) of skim milk was successfully used as a diafiltrant to remove SP from skim milk before cheese making, while maintaining the concentration of lactose, NPN, and nonmicellar calcium. About $95 \%$ of the SP originally in skim milk was removed by combining one $3 \times$ MF stage and two $3 \times$ PUF diafiltration stages. The final $3 \times$ RMF can be diluted with PUF to the desired concentration of casein for traditional cheese making. The PMF from the skim milk was concentrated in a UF system to yield an SP concentrate with protein content similar to a whey protein concentrate, but without residuals from cheese making (i.e., rennet, culture, color, and lactic acid) that can produce undesirable functional and sensory characteristics in whey products. Additional processing steps to this 3-stage MF process for SP removal are discussed to produce an MF skim retentate for a continuous cottage cheese manufacturing process.
\end{abstract}

(Key words: microfiltration, serum protein recovery, diafiltration, native casein)

Abbreviation key: DF = diafiltration, $\mathbf{M F}=$ microfiltration, microfiltered, $\mathbf{N C N}=$ noncasein nitrogen,

Received September 26, 2004.

Accepted December 28, 2004.

Corresponding author: David M. Barbano; e-mail: dmb37@ cornell.edu.

*Use of names, names of ingredients, and identification of specific models of equipment is for scientific clarity and does not constitute any endorsement of product by authors, Cornell University, or the Northeast Dairy Foods Research Center.
$\mathbf{P M F}$ = permeate from microfiltration, $\mathbf{P U F}=$ permeate from ultrafiltration, $\mathbf{R M F}$ = retentate from microfiltration, $\mathbf{R U F}=$ retentate from ultrafiltration, $\mathbf{S P}=$ milk serum proteins, $\mathbf{S P C}=$ serum protein concentrate, WPC = whey protein concentrate, WPI $=$ whey protein isolate.

\section{INTRODUCTION}

Ultrafiltration is used widely in the dairy industry, particularly in the processing of sweet whey. Dairy liquids with high protein content can be produced using UF because water, lactose, NPN, and soluble minerals pass through the UF membrane but casein or milk serum proteins (SP; mostly $\alpha$-lactalbumin and $\beta$-lactoglobulin) do not pass through a UF membrane. Recently, UF has been used commercially on the farm to reduce transportation costs (Howie, 1999). The history of milk UF for Cheddar and Mozzarella cheese making was reviewed by Horton (1997). The goal of UF when first used before cheese making was to reduce heterogeneity of cheese composition when whey was drained from curd, retain more whey proteins in the cheese to increase cheese yield, and decrease pollution from whey protein disposal (Maubois and Mocquot, 1975). Unfortunately, when a high level of whey protein retention was achieved, the flavor and textural properties of hard cheeses (e.g., Cheddar and Mozzarella) were not acceptable for most commercial applications (Covacevich and Kosikowski, 1978). In contrast with Cheddar and Mozzarella cheeses, some soft cheeses (i.e., feta, and Pavé d'Affinois) have been produced successfully using UF (Horton, 1997). Today, the greatest use of UF in the United States dairy industry has been for the production of whey protein concentrate (WPC).

Microfiltration (MF) has not been widely used in the dairy industry. In recent years, interest in the use of MF of milk to remove bacteria, somatic cells, fat, and separate casein from SP has increased because of improved ceramic membranes and uniform transmembrane pressure technology that reduces membrane fouling (Saboya and Maubois, 2000). Bacteria and fat removal from cheese whey and cheese brine are other uses of MF technology (Saboya and Maubois, 2000). 
Successful use of low concentration factor MF before Cheddar cheese making has been reported in several research studies (St-Gelais et al., 1995; Neocleous et al., 2002a,b). Mozzarella cheese has been produced using high concentration factor MF (Brandsma and Rizvi, 2001). Garem et al. (2000) produced a whey proteindepleted skim milk powder with MF for use in countries that have a short milk supply. The low SP powder was a better alternative to skim milk powder for Mozzarella cheese making because $\beta$-lactoglobulin was not present to complex with $\kappa$-CN during thermal processing.

There are many reasons why it might be desirable to remove SP from milk before cheese manufacture. First, most of the SP are not retained in the cheese so removal before cheese making would produce the same cheese composition. Second, the permeate from MF (PMF) from a 0.1- $\mu \mathrm{m}$ membrane is virtually sterile and the proteins are in their native form. Third, the SP liquid produced using MF contains little or no fat and the SP products would not develop the defects associated with fat deterioration during storage. Some whey products contain between 1 and $7 \%$ fat (Huffman and Harper, 1999). The fat content of whey products has a negative effect on flavor (Morr and Ha, 1991) and foaming (Pearce et al., 1992). The off-flavors caused by fat oxidation limit the use of whey products. Lastly, SP may have functional advantages over the same proteins isolated from whey because they would not contain lactic acid, cheese color, and starter culture from the cheese making process (Britten and Pouliot, 1996). Depending on the value of the benefits that SP products have over whey protein products, recovering the SP before cheese manufacture to produce serum protein concentrate (SPC) may be an alternative to WPC or whey protein isolate (WPI) from whey.

Bacher and Kønigsfeldt (2000) produced an "ideal whey" using water diafiltration (DF) during MF, which had improved functional properties (i.e., solubility, foaming, and gelation) compared with WPC and WPI. If removal of serum proteins from milk can produce higher value milk serum protein products, then a process that maximizes the recovery of the SP from milk before cheese making will be needed. The objective of our research was to develop a multistage MF process to achieve a high recovery of serum proteins from skim milk while producing a low concentration factor skim retentate from microfiltration (RMF) with a concentration of soluble minerals, NPN, and lactose similar to skim milk used to standardize milk for use in traditional Cheddar cheese making.

\section{MATERIALS AND METHODS}

\section{Milk Processing}

Milk processing including the subsequent filtration and DF required $2 \mathrm{~d}$ of $1 \mathrm{wk}$ due to the capacity of our equipment. The milk processing and filtration/DF were replicated 3 times. A different batch of milk was used for each replicate.

Pasteurization and separation. Whole raw bovine milk was received on the first day of processing from the Cornell University teaching and research dairy farm. The raw milk was pasteurized at $72^{\circ} \mathrm{C}$ for $15 \mathrm{~s}$ and quickly cooled to $4^{\circ} \mathrm{C}$, using regeneration and cooling sections of a plate heat exchanger system. Next the cooled milk was heated to $50^{\circ} \mathrm{C}$ with a plate heat exchanger then separated into skim and cream using a centrifugal cream separator (model 619, DeLaval, Kansas City, MO). The skim portion was quickly cooled to $4^{\circ} \mathrm{C}$ using a plate heat exchanger and stored overnight at $4^{\circ} \mathrm{C}$.

Process to remove SP. The total MF process (Figure 1) had 3 stages: 1) $3 \times \mathrm{MF}$ of the skim milk, 2) DF using permeate from UF (PUF) as the diafiltrant, and 3) a second DF using PUF as the diafiltrant. On the second day of processing, approximately $300 \mathrm{~kg}$ of pasteurized skim milk (processed the day before) was warmed to $50^{\circ} \mathrm{C}$ using a plate heat exchanger with $60^{\circ} \mathrm{C}$ water as the heating medium and placed in a stainless vat connected to the MF unit. An MF unit capable of maintaining uniform transmembrane pressure (Tetra Alcross M7 Pilot Plant Type, Tetra Pak, Denmark) equipped with $0.1-\mu \mathrm{m}$ nominal pore diameter ceramic Membralox membranes (total area of $1.7 \mathrm{~m}^{2}$ ) was used to remove serum proteins from skim milk. Retentate and permeate MF bleed flow rates were 45 and $90 \mathrm{~L} / \mathrm{h}$, respectively. The MF system consisted of a feed pump, a retentate recirculation pump, and a permeate recirculation pump. The retentate and permeate inlet pressures (corrected for elevation differences) were approximately 422 and $384 \mathrm{kPa}$, respectively, and the retentate and permeate outlet pressures (corrected for elevation differences) were approximately 235 and $218 \mathrm{kPa}$, respectively. The difference between the inlet and outlet transmembrane pressures was maintained between 23 and $28 \mathrm{kPa}$. Conditions on the MF unit were set so that the weight of the RMF would be one-third the skim milk weight. The RMF from stage 1 was collected in stainless steel milk cans. One part RMF was diluted with 2 parts cold $\left(\leq 4^{\circ} \mathrm{C}\right) \mathrm{PUF}$ (Figure 1$)$ using a process similar to that described by Kulozik and Kersten (2002). When the (stage 1) MF feed vat was almost emptied of skim milk, the RMF/PUF mixture was warmed with a plate heat exchanger to $50^{\circ} \mathrm{C}$ and placed into the feed vat. This batch was run through the MF at a $3 \times$ concentration factor and was the first PUF DF step (stage 2). This process (PUF DF) was completed a second time (stage 3 ) in the same manner as stage 2 (Figure 1).

UF to concentrate SP. The PMF $\left(50^{\circ} \mathrm{C}\right)$ was weighed to the nearest gram and placed in the UF feed 


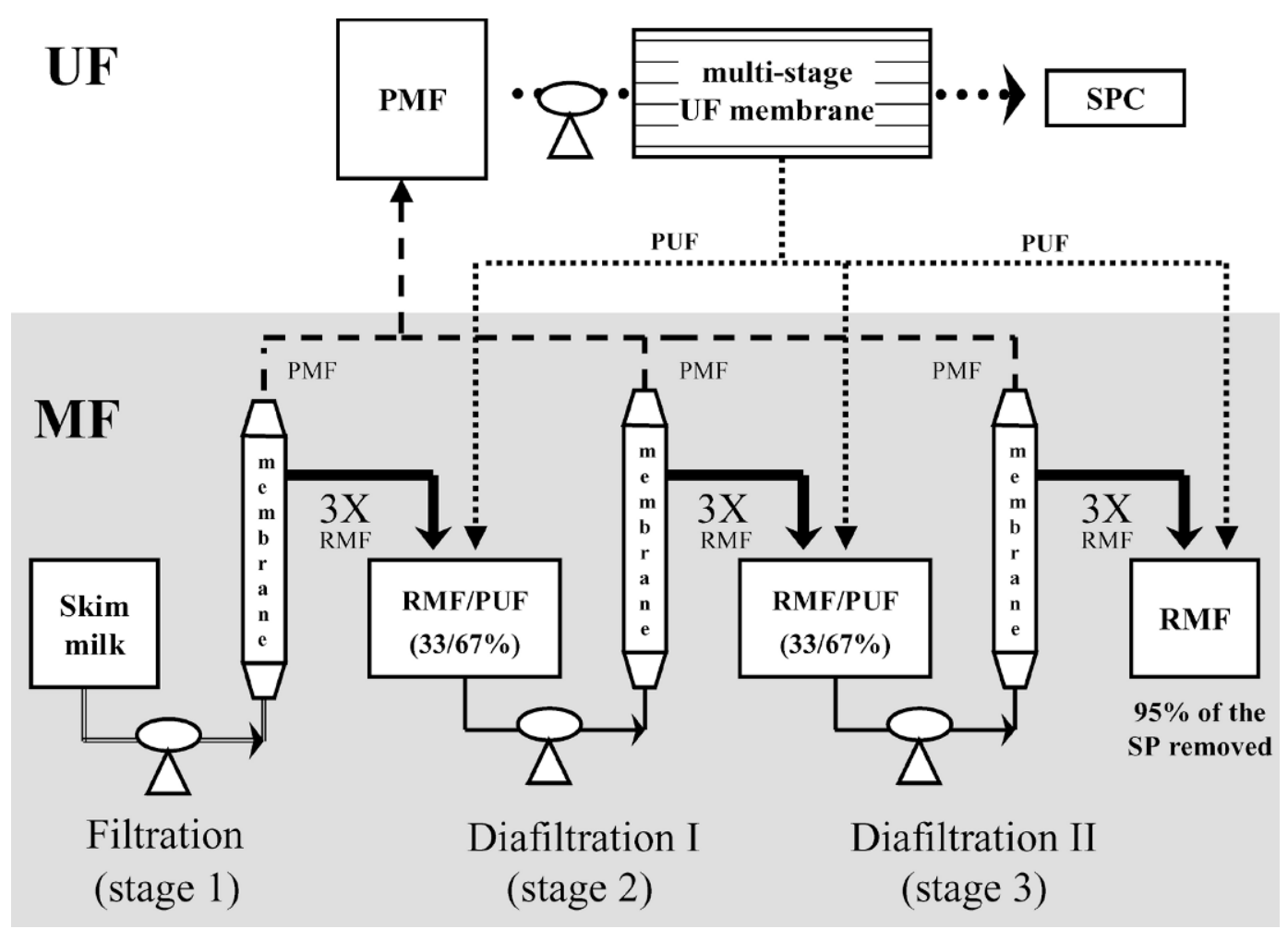

Figure 1. Schematic diagram of a 3-stage process utilizing 1 microfiltration (MF) and 2 diafiltration stages to reduce the serum protein (SP) content of skim milk. In stage 1, skim milk was microfiltered (MF) and the permeate (PMF) was then ultrafiltered (UF). In diafiltration I (stage 2), the retentate from MF (RMF) was diluted back to the original weight of skim milk with the permeate from UF (PUF). The mixture was diafiltered with PUF in diafiltration II (stage 3). The result after diafiltration II was a skim milk with a lower serum protein content.

tank (Figure 1). The UF feed was maintained at $49^{\circ} \mathrm{C}$. The PUF was cooled to $4^{\circ} \mathrm{C}$ with a plate heat exchanger. The cold PUF was used as needed to dilute the RMF back to the original skim milk weight for PUF DF. The retentate from ultrafiltration (RUF) of PMF was concentrated until the feed solution could no longer be concentrated (about 20x) given the batch size and dead volume of our UF system. The UF system was shut off and drained to recover as much of the RUF as possible. The plate-and-frame UF unit (model Dorr-Oliver Iopor Series 'S', Amicon, Beverly, MA) was equipped with twenty-one 10-kDa S-10 polysulfone membranes for UF of PMF with a total UF membrane area of $1.41 \mathrm{~m}^{2}$.

The permeate flux of the UF was so high with PMF (Figure 2) that about $79 \mathrm{~kg}$ of PMF were collected before the UF unit was started, to maintain an adequate amount of UF feed material to keep the UF unit running constantly. Because of this delay in starting the UF portion of the process, PUF produced earlier was required for the addition in the first DF stage in our MF pilot system. This additional PUF was produced before the first week of MF. A batch of skim milk was UF to provide PUF for the first stage of DF. The PUF was placed into 19-L containers and held frozen $\left(-29^{\circ} \mathrm{C}\right)$ for at least $24 \mathrm{~h}$. The containers of PUF were placed in a cooler set at $4{ }^{\circ} \mathrm{C}$ and thawed in about 5 to $6 \mathrm{~d}$. The thawed PUF was moved to another container and the PUF was heated to dissolve any precipitated lactose and minerals in the thawed PUF. The PUF left over from the first and second weeks of processing were frozen and thawed in the same manner for use in the first $\mathrm{DF}$ of the second and third weeks. If this process were done continuously (e.g., in a factory), the freezing and thawing of PUF and some of the heating and cooling steps would not be necessary.

\section{Sample Preparation and Chemical Analysis}

Samples of skim milk were taken from the MF feed vat at the beginning of filtration. The RMF and PMF samples for the first stage were taken after about half of the skim milk was MF. Similarly, the RMF and PMF for the 2 PUF DF stages were taken when about half of the feed was processed. After UF was complete, the RUF left in the feed vat was combined with the RUF drained from the dead volume of the UF system, mixed, 


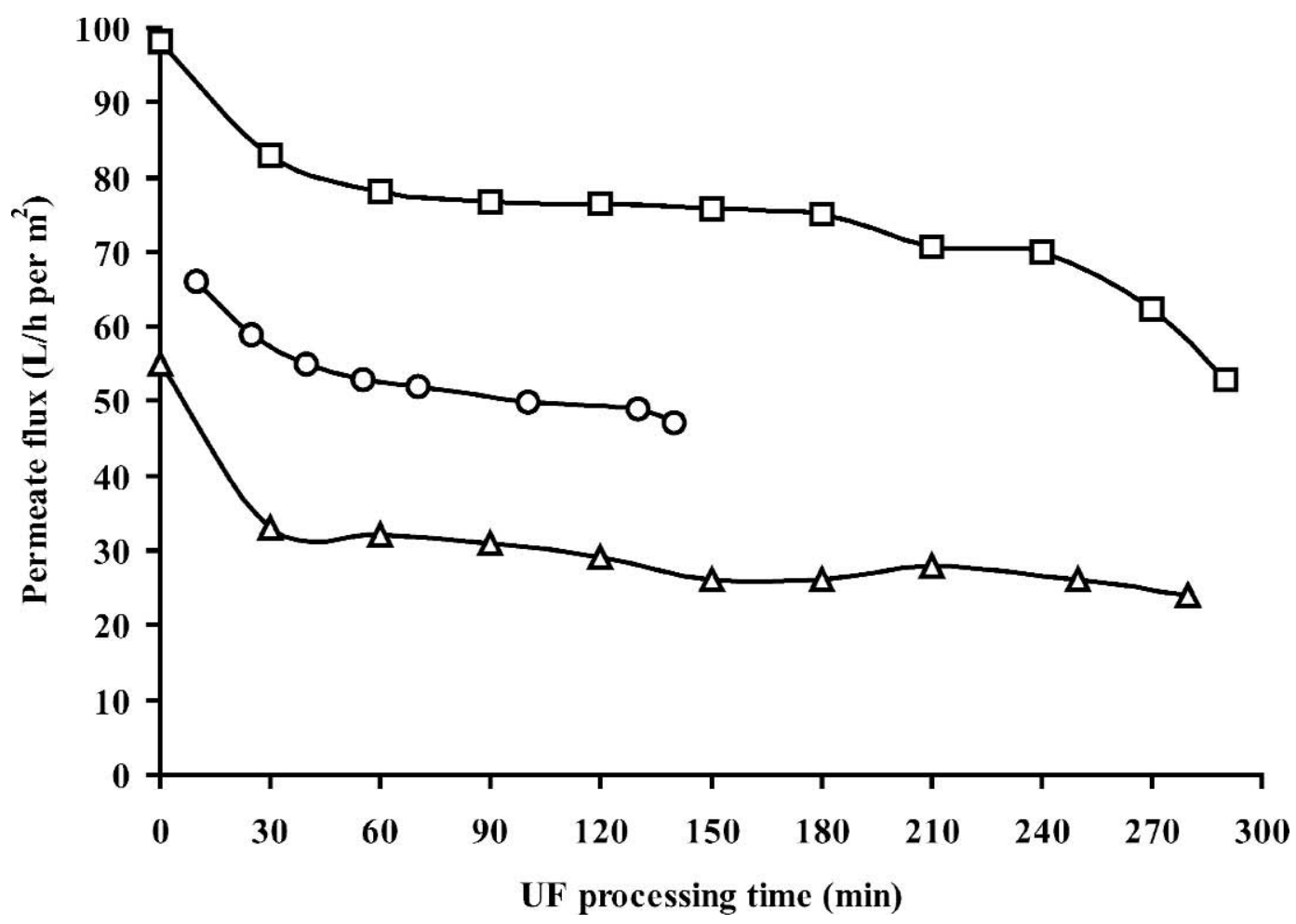

Figure 2. Permeate flux as a function of time during batch ultrafiltration (UF) of permeate ( $\square$ ) obtained from 1 microfiltration stage and 2 diafiltration stages of skim milk. The permeate flux during continuous UF of Cheddar cheese whey ( $\bigcirc)$ and batch UF of skim milk $(\triangle)$ on the same UF system are included for comparison. The concentration factors for the 3 feed solutions permeate from microfiltration, whey, and skim milk were 20,2 , and $2 \times$, respectively. The permeate flux data (collected on the same UF system) for whey from Cheddar cheese manufactured using calf rennet was from Tong et al. (1988).

and sampled. Permeate from UF samples were taken at the end of UF. Samples were placed in 59-mL snap lid vials (Capital Vial, Inc., Fultonville, NY). Samples for nitrogen and TS analysis were analyzed fresh, and all other analyses were performed on frozen samples. The samples were placed in a $-80^{\circ} \mathrm{C}$ freezer overnight and then held at $-40^{\circ} \mathrm{C}$ until analysis. Frozen samples were quickly thawed before analysis using a microwave oven in a manner that kept the temperature of the sample below $10^{\circ} \mathrm{C}$. Once thawed, samples were weighed immediately for analysis.

Fat, TS, total N, NPN, and noncasein nitrogen (NCN) content were determined using ether extraction (AOAC, 2000; 33.2.26, 989.05), forced air oven drying (AOAC, 2000; 33.2.44, 990.20), Kjeldahl (AOAC, 2000; 33.2.11, 991.20), Kjeldahl (AOAC, 2000; 33.2.12, 991.21), and Kjeldahl (AOAC, 2000; 33.2.64, 998.05), respectively. A 3-g sample size was used for RUF for ether extraction and NCN analysis of RMF. All other samples sizes were the same as normally used for milk. Crude protein was calculated by multiplying total $\mathrm{N}$ by $6.38, \mathrm{CN}$ was calculated by subtracting the NCN from the total N then multiplying by 6.38 , and SP content was calculated by subtracting NPN from NCN and then multiplying by
6.38. The calcium content was determined using atomic absorption (Metzger et al., 2000).

\section{SDS-PAGE}

An SDS-PAGE method was used to detect low levels of $\mathrm{CN}$ in the SPC. Because the RUF was concentrated $20 \times$, if CN did pass through the MF membranes it would be easier to detect in the RUF than in the PMF. The RUF $(0.1 \mathrm{~mL})$ was mixed with $0.9 \mathrm{~mL}$ of sample buffer (Verdi et al., 1987). Additionally, 2 samples of RUF were spiked with $1 \% \alpha_{\mathrm{s}}-\mathrm{CN}$ and $1 \% \beta$-CN, respectively. The RUF samples $(0.1 \mathrm{~mL})$ with added $\mathrm{CN}$ were added to $0.9 \mathrm{~mL}$ of sample buffer. Both RUF with and without the CN spike were loaded ( $2 \mu \mathrm{L})$ onto a SDS-PAGE gel prepared according to Verdi et al. (1987), except the separating gel was $15 \%$ acrylamide instead of a gradient.

The Kjeldahl methods mentioned above were designed to analyze normal milk samples. When milk has been fractionated by filtration processes, the usual sample sizes used for the Kjeldahl method may be inappropriate. Usually, a sample size of $10 \mathrm{~mL}$ is used for NCN determination of milk (AOAC, 2000; 33.2.64, 
998.05). The preparation of the sample involves precipitation of the $\mathrm{CN}$ by acetic acid. In this study, only 3 $\mathrm{mL}$ of RMF was used for the NCN method so that approximately the same amount of milk protein would be in the 100-mL flask during precipitation as when the usual $10 \mathrm{~mL}$ of milk is used. An SDS-PAGE method was used to determine if the filtrates from the acid precipitation of RMF contained CN. Noncasein nitrogen filtrates were prepared for SDS-PAGE by adjusting 25 $\mathrm{mL}$ of filtrate to $\mathrm{pH} 6.8$ with a few drops of $5 \mathrm{M} \mathrm{NaOH}$. Then, $0.5 \mathrm{~mL}$ of sample buffer was added to $0.5 \mathrm{~mL}$ of $\mathrm{pH}$-adjusted NCN filtrate. The SDS-PAGE gel was prepared according to Verdi et al. (1987) except that 45 $\mu \mathrm{L}$ of $\mathrm{pH}$-adjusted NCN filtrate in buffer was loaded onto a $15 \%$ acrylamide gel.

An SDS-PAGE method was used to verify the results from Kjeldahl analyses, specifically SP removal, in each stage of the 3-stage process. For this gel, samples were prepared accordingly: $0.1 \mathrm{~mL}$ of skim milk was mixed with $0.9 \mathrm{~mL}$ of sample buffer, $0.1 \mathrm{~mL}$ of RMF (from each stage 1,2 , and 3 ) was mixed with $0.9 \mathrm{~mL}$ of sample buffer, and $0.05 \mathrm{~mL}$ of RUF was mixed with $1.45 \mathrm{~mL}$ of sample buffer. A $15 \%$ acrylamide gel was loaded with 7, 2.3, and $1 \mu \mathrm{L}$ of skim milk, RMF, and RUF sample buffer mixtures, respectively. The differences in loading and sample concentration were done to keep the CN content of the lanes with skim milk and RMF the same and to keep the SP content of the lanes with skim milk and RUF the same.

\section{Serum Protein Recovery}

Mean and standard deviations for the actual recoveries of SP for the 3 replicates were calculated. The PUF added for the $2 \mathrm{DF}$ stages contained a low concentration of SP because the UF membranes allowed a small amount of SP through. This may have been due to small leaks in the UF membranes or nonuniform pore size distribution. The total amount of the SP in the process (Figure 1) was the sum of the SP in the original skim milk and the SP added with the PUF used as a diafiltrant for the first and second DF. The presence of SP in the PUF has been reported (Barbano et al., 1988) and was at a level in our PUF (Table 1) that could not be ignored in recovery calculations. The total amount of SP removed was determined by multiplying the weight of PMF from the respective filtration and DF stages by the respective PMF SP content and then summed. Actual SP recoveries were determined by dividing the total SP removed by the total SP in the process and multiplying by 100 . Theoretical SP removal calculations were done in 2 ways: 1 ) using the skim milk composition from each replicate and a $3 \times$ concentration factor for a 3 -stage process (Figure 1) where PUF would contain a low level of SP (as in our work) and 2) where PUF would be assumed not to contain any SP.

\section{RESULTS AND DISCUSSION}

\section{Retentate and Permeate Composition}

As expected, the fat content of the RMF from all 3 stages of the process was about $3 \times$ the concentration of the fat in the skim milk (Table 1). Fat was not detected in the PMF or the PUF, but was detected in the RUF. Once the PMF was concentrated $20 \times$, the fat in the RUF was detected by our methods and determined to be at a concentration of $0.05 \%$. Therefore, PMF must have contained a small amount of fat, but the majority was retained by the MF membrane and present in the RMF. The CN content of the stage- 3 RMF was 3.1 times the $\mathrm{CN}$ concentration in the skim. The concentrations of the CN in the RMF (Table 1) are not accurate because a low level of intact $\mathrm{CN}$ was detected in the NCN filtrates using SDS-PAGE (data not shown). Therefore, the reported CN content (Table 1) determined by the Kjeldahl method underestimated the $\mathrm{CN}$ content of the RMF and overestimated the SP content of the RMF at each stage.

After each of the 3 processing stages, the SP content of the RMF and PMF decreased (Table 1 and Figure 3). Removal of SP from RMF would also have occurred using water as the diafiltrant, but using water as a diafiltrant would have reduced the concentration of other soluble components of milk in the RMF. Maintaining a normal concentration of the lactose, NPN, and calcium content of the RMF was very important for maintaining a normal balance of these constituents in RMF that would be used for traditional cheese making. The SP are not necessary for cheese manufacture. Lactose and NPN are necessary for acid production and starter culture growth. Soluble calcium is needed for coagulum formation and cheese texture. With PUF as a diafiltrant, the NPN concentration in the RMF was maintained throughout the 3 -stage process (Figure 1) at a level similar to skim milk (Table 1). Although lactose was not measured directly, we expect that lactose would pass freely through the membranes, as does NPN. The $0.03 \%$ calcium content of the PUF was about one-third the total calcium content of the skim milk, which was the expected proportion of nonmicellar calcium in milk.

The PMF was not analyzed for NCN, because the NCN procedure was not designed to work on this matrix or at very low levels of $\mathrm{CN}$ in dilute solutions. The protein banding pattern of RUF with SDS-PAGE is shown in Figure 3. In Figure 3, the skim milk and RUF samples were prepared and lanes loaded in a manner that kept the SP contents in these lanes equal (as ex- 
Table 1. Means $(\mathrm{n}=3)$ and standard deviations of skim milk, retentate from microfiltration (RMF), and permeate from microfiltration $(\mathrm{PMF})$ composition after microfiltration of skim milk and 2 diafiltration steps with permeate from ultrafiltration $(\mathrm{PUF})$. The means $(\mathrm{n}=3)$ and standard deviations of the retentate from ultrafiltration (RUF) and PUF compositions after the second diafiltration step are also shown.

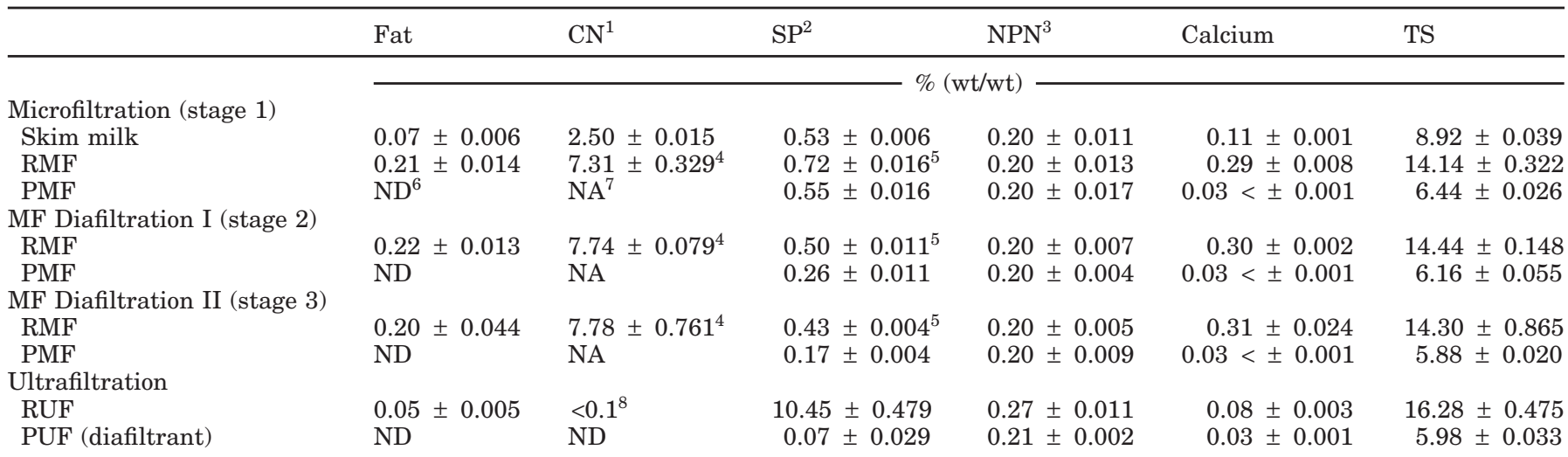

${ }^{1} \mathrm{CN}=$ Total nitrogen minus noncasein nitrogen with the difference multiplied by 6.38 .

${ }^{2} \mathrm{SP}=$ Serum protein.

${ }^{3} \mathrm{NPN}=\mathrm{NPN} \times 6.38$.

${ }^{4}$ Underestimated as explained in the Results and Discussion.

${ }^{5}$ Overestimated as explained in the Results and Discussion.

${ }^{6} \mathrm{ND}=$ Not detected $(<0.002 \%)$.

${ }^{7} \mathrm{NA}=$ Not analyzed, the method was not appropriate for this sample matrix.

${ }^{8}$ Estimated from SDS-PAGE.

plained in the Materials and Methods section). Under these conditions, the CN bands of the RUF were faint (Figure 3). The $20 \times$ RUF was run separately on another

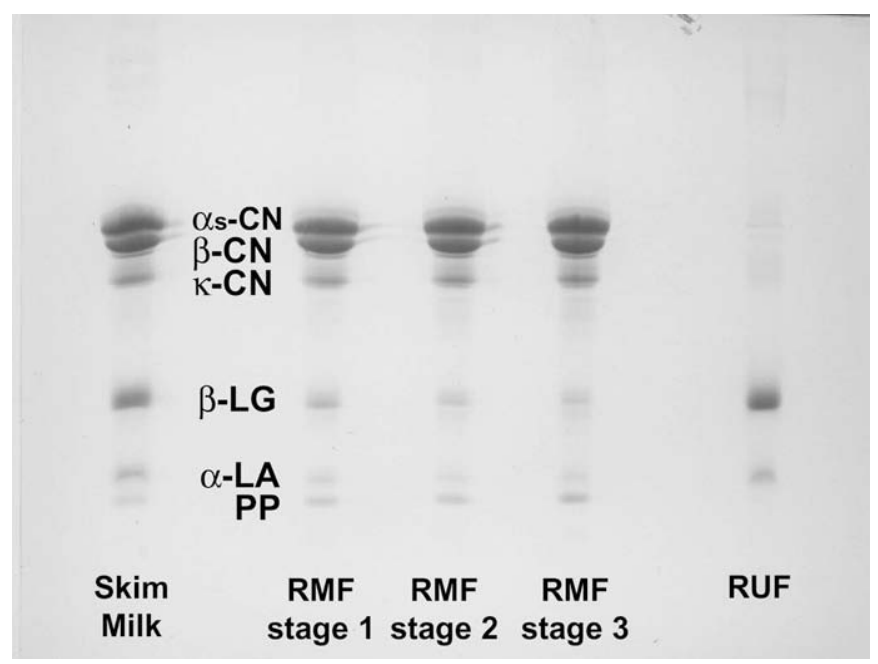

Figure 3. The proteins in skim milk, retentate from the microfiltration $(\mathrm{RMF})$ of skim milk, and $20 \times$ retentate from the ultrafiltration (RUF) of permeate from the microfiltration of skim milk separated using SDS-PAGE. The RMF samples were collected after the completion of $3 \times$ microfiltration (stage 1 ), diafiltration of the RMF from stage 1 with permeate from ultrafiltration (stage 2), and diafiltration of the RMF from stage 2 with permeate from ultrafiltration (stage 3). Bands are identified on the gel: $\alpha_{\mathrm{s}} \mathrm{CN}=$ combination of $\alpha_{\mathrm{s} 1}$ and $\alpha_{\mathrm{s} 2}$-CN, $\beta$-LG $=\beta$-lactoglobulin, $\alpha$-LA $=\alpha$-lactalbumin, and $\mathrm{PP}=$ proteolysis product. gel with and without $1 \%$ added $\alpha_{\mathrm{s} 1}-\mathrm{CN}$ and $1 \%$ added $\beta$-CN (data not shown). The CN bands on the SDSPAGE gel for the 20× RUF samples with $1 \%$ added CN were compared visually with the $20 \times$ RUF samples without added $\mathrm{CN}$. The faint $\mathrm{CN}$ bands visible in the $20 \times$ RUF samples looked similar or less intense than

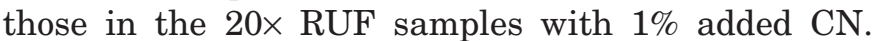
Therefore, the CN content of the 20× RUF was estimated at $\leq 1 \%$ of the true protein, or a concentration of $<0.1 \%$ in the RUF. The $20 \times$ RUF is an SP concentrate. About $64 \%$ of the TS were protein when the PMF was concentrated to about $20 \times$ by UF. The calcium concentration in the SPC was about $73 \%$ of that of skim milk. The PUF used as the diafiltrant contained about 3 times more SP (Table 1) than reported in PUF by Barbano et al. (1988). Barbano et al. (1988) concluded that PUF contained SP because UF membranes contain some pores that were larger than the nominal pore size and allowed some lower molecular weight proteins (e.g., $\alpha$ lactalbumin) to pass through the membrane.

A low molecular weight casein proteolysis product typically migrates ahead of $\alpha$-lactalbumin in a milk sample on our SDS-PAGE gels (Figure 3). Interestingly, this small proteolysis product was not visible in the SPC but was visible in the RMF. This suggests that the hydrophobic nature of this protein fragment (that has a lower molecular weight than $\alpha$-lactalbumin) may cause it to remain associated with the micelle at $50^{\circ} \mathrm{C}$ during MF instead of passing through the MF mem- 
Table 2. Mean $(\mathrm{n}=3)$ actual and theoretical removal of serum proteins (SP) from skim milk by microfiltration and diafiltration with permeate from ultrafiltration (PUF).

\begin{tabular}{llll}
\hline & & \multicolumn{2}{c}{$\begin{array}{c}\text { Theoretical } \\
\text { SP removal }\end{array}$} \\
\cline { 2 - 4 } & & $\begin{array}{l}\text { Diafiltrant, } \\
\text { PUF, }\end{array}$ & $\begin{array}{l}\text { Diafiltrant, } \\
\text { PUF, } \\
\text { contains } \\
\text { no SP }\end{array}$ \\
& $\begin{array}{l}\text { Actual SP } \\
\text { removal }\end{array}$ & $\begin{array}{l}0.07 \% \text { SP } \\
\text { non }\end{array}$ & \\
\cline { 2 - 4 } & & 57 & 67 \\
Filtration (stage 1) & $56 \pm 2.5$ & 24 & 22 \\
Diafiltration I (stage 2) & $24 \pm 1.8$ & 24 & 7 \\
Diafiltration II (stage 3) & $15 \pm 1.5$ & 13 & 96 \\
Total & $95 \pm 1.1$ & 94 & \\
\hline
\end{tabular}

brane. More research is needed to determine if the removal of the plasmin inhibitor (i.e., $\beta$-lactoglobulin; Bastian et al., 1993) during MF may accelerate the $\mathrm{CN}$ hydrolysis by plasmin during storage of the RMF after processing.

\section{SP Removal}

The 3-stage process (Figure 1) removed $95 \%$ of the SP from skim milk (Table 2). The SP removal was determined based on the SP content of the original skim milk and PMF, not the RMF, because of the presence of $\mathrm{CN}$ in the NCN filtrates of the acid precipitated RMF, which results in an underestimation of the SP removal. The PMF contained a very small amount of $\mathrm{CN}$ (CN was found in the SPC using SDS-PAGE at $\leq 1 \%$ of the true protein) and this amount of $\mathrm{CN}$ would have little influence on the SP removal calculations. The process reported by Garem et al., 2000 to produce a whey protein-depleted skim milk powder appears to achieve a removal (i.e., 67\%) similar to that achieved in the first stage of the process reported in Table 2 before PUF was added for DF I. A 3-stage process (Figure 1) yields 95 $\pm 1.1 \%$ SP removal from skim milk when there is a small amount of SP added with the PUF, as was the case in this study (Table 2 and Figure 3). An SP removal of $96 \%$ would be expected from a 3 -stage process (Figure 1) with no added SP from the diafiltrant (Table 2) but would produce a RMF with a lower final SP content. The amount of SP removed by each stage as a percentage of the total SP can be explained by accounting for the additional SP added with the PUF (Table 2). A PUF without SP would be ideal for the best possible SP recovery. Although Kulozik and Kersten (2002) indicated that it is theoretically possible to achieve higher removal of SP, this will be limited in a practical sense by the low level of SP present in UF permeate. Processors would need to consider whether the value of the remaining SP (4 to $6 \%$ of the original SP) in the RMF would warrant the cost of adding a fourth stage (i.e., DF III) to the process.

\section{MF and UF Flux}

During MF (stage 1) and DF (stages 2 and 3), transmembrane pressures at the inlet and outlets of the retentate and permeate as well as bleed rates were maintained during the 6-h MF processing run because of uniform transmembrane pressure technology. Permeate flux during UF of the PMF was much higher (about $80 \mathrm{~L} / \mathrm{h}$ per $\mathrm{m}^{2}$ ) than when whey (about $55 \mathrm{~L} /$ $\mathrm{h}$ per $\mathrm{m}^{2}$ ) and skim milk (about $30 \mathrm{~L} / \mathrm{h}$ per $\mathrm{m}^{2}$ ) were processed on the same system (Figure 2). The low levels of fat and CN in PMF (Table 1) and the absence of lactic acid, glycomacropeptide, starter bacteria, and coagulant would all contribute to higher flux during the 5-h UF processing run of PMF than when processing whey. Even near the end of the processing run, when the RUF was approaching $20 \times$, the flux remained higher than when processing whey or skim milk to $2 \times$. Therefore, it would take less UF membrane surface area to concentrate SP removed from skim milk vs. concentrating the same amount of SP when they are in whey.

\section{PMF of Skim Milk vs. Sweet Whey}

The protein and calcium content of sweet whey is about the same as the PMF of skim milk. The fat content of PMF (Table 1) was much lower than the 0.23 to $0.49 \%$ reported for sweet whey from Cheddar cheese (Barbano and Sherbon, 1984). Even when Cheddar cheese whey is separated using a centrifugal cream separator, the separated whey contains more fat (about 0.05 to $0.07 \%$ ) than PMF. Using the Van Slyke theoretical yield formula for Cheddar cheese, one can estimate the amount of $\mathrm{CN}$ as a percentage of true protein in sweet whey. According to the Van Slyke formula, the percentage of $\mathrm{CN}$ in the milk minus 0.1 will be recovered in the cheese. Therefore, for milk with $2.5 \% \mathrm{CN}, 4 \%$ of the weight of $\mathrm{CN}$ in the milk will be in the whey and will be present mostly as glycomacropeptide produced by the action of chymosin on $\kappa$-CN. If milk for Cheddar cheese making contained $0.5 \%$ SP, then the CN would be about $17 \%$ of the true protein in the sweet whey. The $\mathrm{CN}$ content of the SPC that contained $10.45 \%$ true protein (Table 1) in our study was $\leq 1 \%$ of the true protein (i.e., $\leq 0.105 \%$ of the SPC). Therefore, SPC has a lower CN content than WPC. Sweet whey also contains starter culture, color, lactic acid, and coagulant but PMF and SPC from that PMF do not.

Not all of the PUF produced by the UF of PMF will be needed for DF. Lactose from PUF will be more pure and will require less washing to produce high purity 


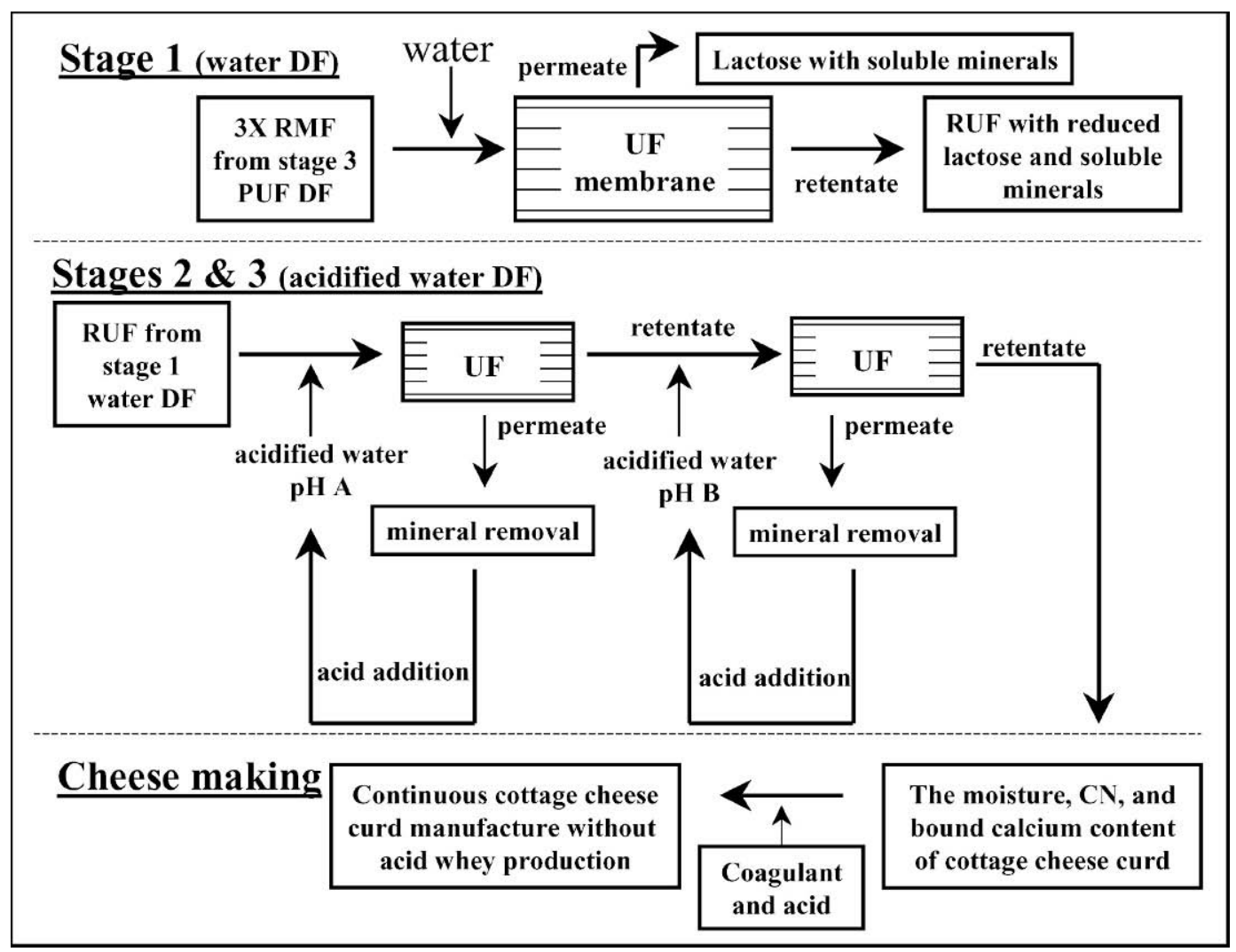

Figure 4. Schematic of a process that would follow the one shown in Figure 1. This process would use a water diafiltration step and 2 acidified water diafiltration steps to produce a retentate from ultrafiltration (RUF) that would have the composition of cottage cheese curd. The net result after filtration and cheese making would be the elimination of acid whey from cottage cheese manufacture.

lactose than that from cheese whey because of the absence of impurities from the cheese making process. This should produce a higher recovery of lactose crystals and less lactose in delactosed permeate. In addition, the delactosed permeate will not contain lactic acid.

The RMF after the third stage (Figure 1) could be diluted with PUF to a concentration that is realistic to use in conventional cheese making. The whey from this cheese making would contain a high percentage of its true protein as glycomacropeptide and could be used to produce a glycomacropeptide concentrate using UF as suggested by Thomä and Kulozik (2004).

\section{Future Possibilities: Serial Elution DF}

Some further possibilities for application of membrane filtration technologies can be illustrated in an example of filtration and DF before cottage cheese manufacture. Acid whey is a difficult to process and lowvalue by-product that plagues cottage cheese manufacturers. Because of the high acid content, options for use of acid whey are limited compared with sweet whey produced from Cheddar and Mozzarella cheeses. Therefore, a processing strategy that would eliminate acid whey production in cottage cheese manufacture and recover SP from milk before cheese making would eliminate this problem.

A theoretical design of a continuous process for cottage cheese production combines the process in Figure 1 with that shown in Figure 4. The concentrations of milk components, except lactose, required for continuous production of cottage cheese curd will be their concentration in the cheese curd at the end of cooking in the traditional cottage cheese making process (Kosikowski and Mistry, 1997). Traditional production of cottage cheese curd starts with skim milk (Kosikowski and Mistry, 1997) and produces about 6.4 to $7.3 \mathrm{~kg}$ of curd at about 80 to $82 \%$ moisture and 38.1 to $39.0 \mathrm{~kg}$ of acid whey (Klei et al., 1998). With the composition of cottage cheese curd (Klei et al., 1998) as a goal (i.e., 17 to $18 \%$ TS and 15 to $16 \%$ protein), the MF of skim milk by the process in Figure 1 would be the first step. Thus, 94 to $96 \%$ of the SP would be removed from the skim milk as a pure product without acid contamination as the first step in a new approach to cottage cheese manufac- 
ture. The lactose concentration in skim milk is higher than is necessary for cottage cheese curd formation and flavor because most of the lactose is lost into the acid whey during traditional cottage cheese making. The mineral content of the milk needs to be reduced to the concentration found in the curd, and the protein concentration in the final retentate could be controlled to be equal to that normally found in cottage cheese curd. This concept is similar to earlier approaches to high concentration factor UF for cheese making (Maubois and Mocquot, 1975). The results of this milk component separation will produce high purity SP and lactose with higher value than when these components are present in acid whey from traditional cottage cheese making.

The approach to eliminate acid whey production is outlined in Figures 1 and 4. The PUF DF is used (Figure 1) to remove SP from skim milk (instead of water) to reduce the demand for water to remove SP. After the third stage of PUF DF using MF, the final $3 \times \mathrm{MF}$ retentate from Figure 1 would be water DF using a UF system (stage 1 in Figure 4) to remove most of the remaining lactose. Acidified water (e.g., with lactic acid) would be used in the second and third UF/DF stages (Figure 4) to serially elute the calcium from the UF retentate. The third UF/DF stage would use water acidified to a lower $\mathrm{pH}$ than in the second stage to further reduce the mineral content of the retentate. The acidified water diafiltrants would be processed to remove the minerals and the water and lactic acid would be recycled in the diafiltration. Thus, most of the acid would be reused. The water phase of the retentate exiting stage 3 (Figure 4) would contain about the normal amount of lactic acid found in cottage cheese curd, but it would not be produced by a culture. No acid development by culture would be required for curd manufacture. The target ending $\mathrm{pH}$ would have to be determined experimentally to be just high enough to avoid coagulation at this point. The liquid retentate composition would be approximately that of an uncreamed cottage cheese curd. The final UF retentate in Figure 4 (i.e., liquid precheese) would flow into a dynamic mixing chamber where a low concentration of rennet (and additional acid if needed) would be injected and mixed before moving into a continuous coagulation section of a cottage cheese coagulator. With a residence time of a few minutes in the coagulator, cottage curd would be continuously extruded from the coagulator and there would be little or no whey drainage from the curd. Thus, acid whey production could be eliminated. A cream dressing would be produced separately by normal cottage cheese manufacturing procedures (Kosikowski and Mistry, 1997) and could be cultured to provide the typical cultured cottage cheese flavor achieved by the traditional process. The culture in the cream dressing could be left active or could be heat-inactivated before mixing the cream dressing with the curd. Temperature control of the curd and cream dressing at the point of mixing would be important for proper absorption of the cream dressing. Finally, addition of a low concentration of $\mathrm{CO}_{2}$ to the cream dressing and barrier packaging of the product will produce a long shelf-life product (Hotchkiss and Lee, 1996) and at the same time eliminate the production of acid whey.

\section{CONCLUSIONS}

A 3-stage MF process was developed that removed 94 to $96 \%$ of the SP from skim milk before cheese making. The SPC product does not contain residual coagulant, starter culture, lactic acid, or color from cheese making. The SPC can be concentrated to any level of protein to produce products similar to the range of WPC and WPI products currently in the market. The RMF is a $\mathrm{CN}$ concentrate that contains a concentration of lactose, NPN, and soluble minerals similar to skim milk so it can be adjusted with UF permeate to any lower concentration factor and be used in conventional Cheddar or Mozzarella cheese making equipment. Further development of this process could be adapted to continuous production of cottage cheese without acid whey production.

\section{ACKNOWLEDGMENTS}

The authors thank Tom Burke, Maureen Chapman, Mark Elwell, Laura Landolf, Bob Kaltaler, Kerry Kaylegian, Joanna Lynch, and Pat Wood for technical and lab assistance and the Northeast Dairy Foods Research Center and Dairy Management Incorporated (Rosemont, IL) for partial financial support.

\section{REFERENCES}

Association of Official Analytical Chemists. International. 2000. Official Methods of Analysis. 17th ed. AOAC, Gaithersburg, MD.

Bacher, T., and P. Kønigsfeldt. 2000. WPI by microfiltration of skim milk. Eur. Dairy Mag. 5:14-16.

Barbano, D. M., V. Sciancalepore, and M. A. Rudan. 1988. Characterization of milk proteins in ultrafiltration permeate. J. Dairy Sci. 71:2655-2657.

Barbano, D. M., and J. W. Sherbon. 1984. Cheddar cheese yields in New York. J. Dairy Sci. 67:1873-1883.

Bastian, E. D., K. G. Hansen, and R. J. Brown. 1993. Inhibition of plasmin by $\beta$-lactoglobulin using casein and a synthetic substrate. J. Dairy Sci. 76:3354-3361.

Brandsma, R. L., and S. S. H. Rizvi. 2001. Manufacture of Mozzarella cheese from highly concentrated skim milk microfiltration retentate depleted of whey proteins. Int. J. Food Sci. Technol. 36:611-624.

Britten, M., and Y. Pouliot. 1996. Characterization of whey protein isolate obtained from milk microfiltration permeate. Lait 76:255-265. 
Covacevich, H. R., and F. V. Kosikowski. 1978. Mozzarella and Cheddar cheese manufacture by ultrafiltration principles. J. Dairy Sci. 61:701-709.

Garem, A., P. Schuck, and J. Maubois. 2000. Cheesemaking properties of a new dairy-based powder made by a combination of microfiltration and ultrafiltration. Lait 80:25-32.

Horton, B. S. 1997. Whatever happened to the ultrafiltration of milk? Aust. J. Dairy Technol. 52:47-49.

Hotchkiss, J. H. and E. Lee. 1996. Extending shelf-life of dairy products with dissolved carbon dioxide. Eur. Dairy Mag. 8:16, 18-19.

Howie, M. 1999. Reverse osmosis, ultrafiltration decrease transportation costs. Feedstuffs 71:33, 10.

Huffman, L. M., and W. J. Harper. 1999. Maximizing the value of milk through separation technologies. J. Dairy Sci. 82:2238-2244.

Klei, L., J. Yun, A. Sapru, J. Lynch, D. Barbano, P. Sears, and D. Galton. 1998. Effects of milk somatic cell count on cottage cheese yield and quality. J. Dairy Sci. 81:1205-1213.

Kosikowski, F. V., and V. V. Mistry. 1997. Cottage Cheese. Pages 127-146 in Cheese and Fermented Milk Foods. Vol 1. 3rd ed. F. V. Kosikowski, LLC. Westport, CT.

Kulozik, U., and M. Kersten. 2002. New ways for the fractionation of dairy and minor constituents using UTP-membrane technology. Pages 37-42 in Bulletin of the IDF 374. International Dairy Federation, Brussels, Belgium.

Maubois, J. L., and G. Mocquot. 1975. Application of membrane ultrafiltration to preparation of various types of cheese. J. Dairy Sci. 58:1001-1007.

Metzger, L. E., D. M. Barbano, M. A. Rudan, and P. S. Kindstedt. 2000. Effect of preacidification on low fat Mozzarella cheese. I. Composition and yield. J. Dairy Sci. 83:648-658.
Morr, C. V., and E. Y. W. Ha. 1991. Off-flavors of whey protein concentrates: A literature review. Int. Dairy J. 1:1-11.

Neocleous, M., D. M. Barbano, and M. A. Rudan. 2002a. Impact of low concentration factor microfiltration on milk component recovery and Cheddar cheese yield. J. Dairy Sci. 85:2415-2424.

Neocleous, M., D. M. Barbano, and M. A. Rudan. 2002b. Impact of low concentration factor microfiltration on composition and aging of Cheddar cheese. J. Dairy Sci. 85:2425-2437.

Pearce, R. J., S. C. Marshall, and J. A. Dunkerley. 1992. Reduction of lipids in whey protein concentrates by microfiltration-Effect on functional properties. Page 118-129 in International Dairy Federation, Special Issue 9201. International Dairy Federation, Brussels, Belgium.

Saboya, L. V., and J. L. Maubois. 2000. Current developments of microfiltration technology in the dairy industry. Lait 80:541-553.

St-Gelais, D., M. Piette, and G. Belanger. 1995. Production of Cheddar cheeses using milk enriched with MF milk retentate. Milchwissenschaft 50:614-618.

Thomä, C., and U. Kulozik. 2004. Methods of obtaining isolated caseinomacropeptide from milk and whey and functional properties. Pages 74-77 in Bulletin of the IDF 389. International Dairy Federation, Brussels, Belgium.

Tong, P. S., D. M. Barbano, and W. K. Jordan. 1988. Permeate flux during ultrafiltration of whey: Influence of milk coagulant used for cheese manufacture. J. Dairy Sci. 71:2342-2348.

Verdi, R. J., D. M. Barbano, and M. E. Dellavalle. 1987. Variability in true protein, casein, nonprotein nitrogen, and proteolysis in high and low somatic cell count milks. J. Dairy Sci. 70:230-242. 